\title{
Using modern techniques for determining the location of marketing outlet for product of the state company for vegetables oil
}

Assistant professor Dr.

Abdul muneem k. Hamadi Alshokri

Statistical department -Administration and economic collage Baghdad

University

تاريخ التقديم:2017/3/29

تاريخ القبول:2017/5/11

\section{Abstract :}

Were arranged this study on two sections, which included first section comparison between markets proposed through the use of transport models and the use of the program QSB for less costs, dependant the optimal solution to chose the suggested market to locate new market that achieve lower costs in the transport of goods from factories (ALRasheed,ALAmeen, AlMaamun ) to points of sale, but the second part has included comparison of all methods of transport (The least cost method, Vogels method, Results Approximations method, Total method) depending on the agenda of transport, which includes the market proposed selected from the first section and choose the way in which check the solution first best suited in terms of costs and then subjecting the solution first to test a way distribution adjusted to reach the fitness in the distribution of products from sites to points of sale and end of the second topic is the comparison between the result of the program ( WIN QSB) and the result of the best solution to the transportation method which is better in terms of costs.

being diagnosed with the imbalance in the factories Company for vegetable oils, which leads to the flux productive products ((Shampoo, ALzahe, Sebon Alsail, Sebon Alger, Sebon Altiwlet, Mesahok Algesel, Alkaser) researcher suggested opening a new market for the disposal of flood productive quotient of these products after consultation with officials of the marketing department of the company and identify places proposed that in the interest of discharge flood productive happening in addition to the company's need to open markets in such places, has been to locate this market using transport models through the comparison between the markets of the proposed and deliver these products to market at less cost , and the researcher has a practical application of the use of modern methods and mathematical techniques to locate the proposed market based on data obtained from the company for the year 2011 and for the abovementioned products.

Keywords/ Transportation model, linear programming, Sources , Destination, Location, Optimal solution.

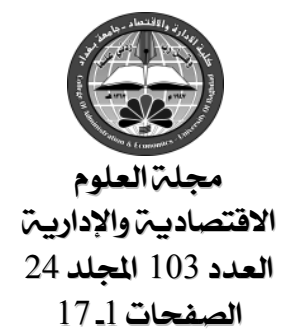




\section{Using modern techniques for determining the location of marketing outlet for product of the state company for vegetables oil}

\section{1 - (Introduction)}

In order to raise the level of production in the country and compete with the rest of the imported products and keep abreast of the industrial and commercial development that took place in most countries of the world, it is necessary to use modern scientific methods and advanced in the process of marketing these products to make the local product rise to real competition with the imported products. The most important problems effected by the management of any institution or facility is how to make the best decision, such as the decision is to maximize profits or reduce costs or increase production capacity or reduction of stocks.

The field of practical application was chosen in the General Company for Vegetable Oil Industry to apply the modern scientific methods in the management of production and marketing, which are lacking by the most local companies, which need such methods to raise the level of production more than it is currently and get rid of the old methods used in marketing management Which depends on the experience and guessing most often in the design of the marketing plan note that the company mentioned is one of the giant companies in the country and has a long sales in the production process has been covering the country's needs of its products and for a long time and is now in need of modern scientific methods to rise to a high level in industry National and competitive products are imported kind and price.

It was proposed to open a new market according to modern accounting standards using transport methods, which is one of the most important problems addressed by linear programming to achieve the lowest costs in discharging the production effluence.

The researcher relied on data collection on the company's database, which includes cost accounting records, planning and follow-up records, marketing records, inventory control records, research and development department, and the benefit of the production plant officials through field co-operation during the production process.

\section{The Methodology :}

\section{2 - Determinant a transport strategy}

Linear programming models have been used in many economic problems, whether productive, financing or administrative, as they help to solve the problems of allocating scarce resources between alternative uses, so that this distribution achieves the maximum efficiency and is used in scheduling production or in making decisions related to The key functions of the Department such as planning, organization and oversight.

Linear programming contributes to the solution of transport and distribution issues as it is used to reach the lowest cost or less time when transferring and distributing production to other $\operatorname{areas}^{(5)}$. 
The issue of transport is one of the important linear programming applications, as it is concerned with the distribution of units or products from several sources of supply (laboratories, centers, marketing centers) to several locations of demand (consumer centers) at the lowest possible cost or at the highest profit or at the lowest time.

The problem of transporting products and distributing them in the markets or to warehouses and warehouses is one of the most important problems that the administrations of the business organizations seek to solve and make the total transport cost as low as possible. The efficiency of the organization in minimizing the cost of the transportation plan provides it with a better opportunity to compete, The cost of transportation is often a component of costs that raise the price and thus make the position of the business organization less competitive with other organizations.The first transport model from (Hitchcock) was developed in 1941 in his named study. (The distribution of a product from several sources to numerous localities) . It was followed by another study by( Koopmans) in 1947. In 1953, (Koopmans, Cooper and Charnes) contributed to the development of methods for testing the solution.

\section{3 - Transportation model/}

The transport model aims to define a single commodity transfer plan from a number of (sources) to a number of (destination) locations. The model data includes the following:

1 - 1the level of supply in each source, and the amount of demand in each place of demand.

2 - The cost of transferring the unit of the commodity from each source to the places of demand.

Since there is only one commodity, the order center can obtain the required quantity from one supply source or from a number of supply sources. The main objective of the model is to determine the amount to be transferred from the designated supply to the designated request center for the lowest total cost of transport.

The model is based on a basic assumption that the cost of transportation on a certain path is not directly related to the number of units transferred on this track (ie, the cost of moving the unit is not affected by the number of units transferred). It is a network consisting of (m) a number of sources of supply and (n) a number to destination, the following figure represent the distribution from sources to destination $(12,11,10,8,7,1)$. 

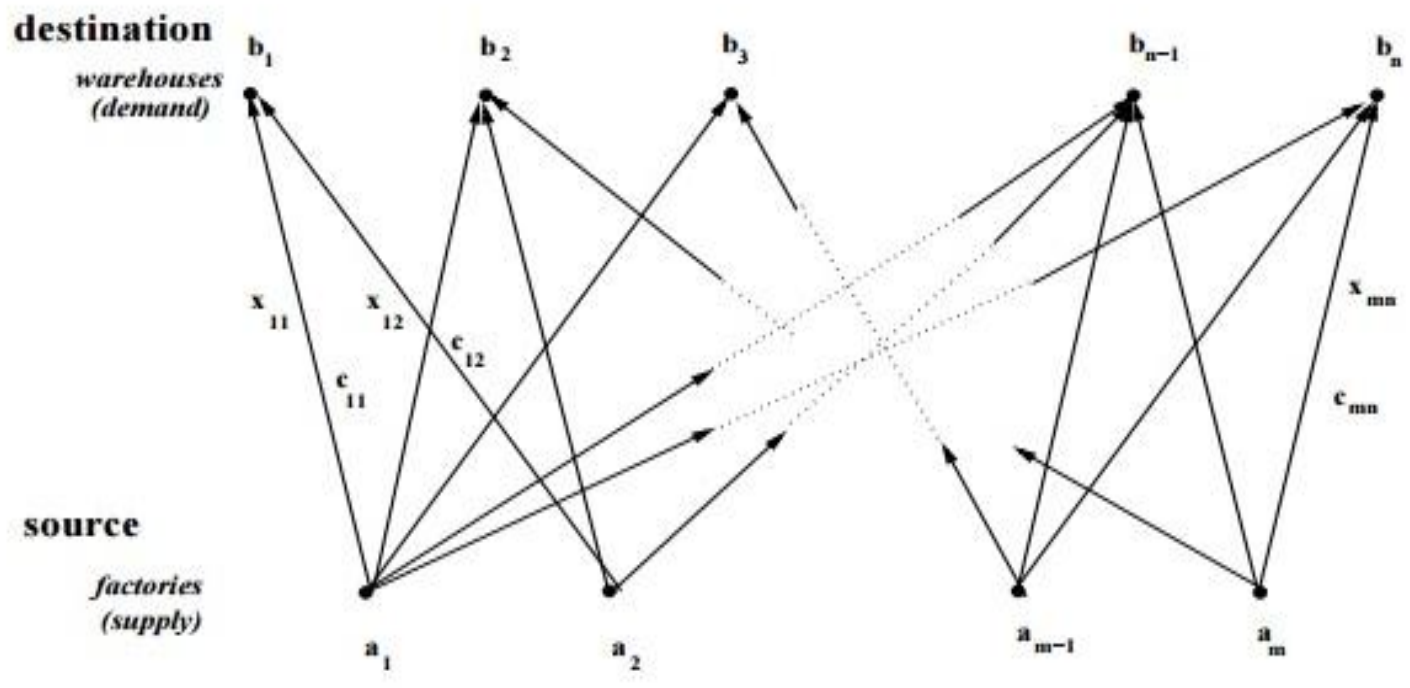

Figure ( 1 ) Represent the transportation of goods from sources to destination .

The reference :(( Al-Shamarti Saad )).

Each bid or request is represented by a circle and the arrow that arrives at the offer represents the path through which the item will be transferred as the figure shows that the quantity shown in source $i$ is ai and that the quantity requested from the place of demand ( $\mathbf{j})$ is $b_{j}$. Thus ( $\left.c_{i j}\right)$ is the cost of moving the unit from source (i) to the place of request $(j)$ and assuming that $\left(X_{i j}\right)$ represents the amount transferred from source $(i)$ to the place of request $(j)$. 3- 1 The general form of the linear programming model representing the transport problem

$$
\text { Minimization } Z=\sum_{i=1}^{m} \cdot \sum_{j=1}^{n} c_{i j X_{i j}}
$$

\section{S.T}

$\sum_{j=1}^{n} X_{i j}=a_{i} \quad, i=1,2, \ldots m$

$\sum_{i=1}^{m} X_{i j}=b_{j} \quad, j=1,2, \ldots n$

for all ( i) and ( j ) ، $\geq 0 \quad X_{i j}$

The first set of restrictions requires that the total amount transferred from the designated source cannot exceed the supply available in that source. 
The second set of restrictions requires that the total amount transferred to the designated application center must meet the requirements of that request.This model implies that the total supply must be at least equal to the total demand. When the total supply is equal to the total demand, this-called (balanced transport model) will be produced. In practice, the supply is not necessarily equal to or greater than demand. In any case, The balancing process is important in developing a method of solution that takes advantage of the special structure of the transport model as well as the possibility of formulating specific operational situations in the form of the transport model .

\section{3- 2 Transportation Problems Solution :}

Transport problems are solved by finding the first basic solution which represents the first stage of the solution. In the second stage, the primary transport is selected and the solution to the optimal solution for transport problems $(10,7,4,3,2)$.

\section{A) The first stage:}

\section{Finding An Initial Solution.}

It is common knowledge that the number of fundamental variables in any primary solution is equal to the number of constraints. However, in terms of transport with $(m+n)$ of constraints and $(m * n)$ of variables hence number basic variables of infeasible initial solution, $(m+n-1)$. The reason for this is the existence of $(m+n-1)$ of the independent equations for the transport issue. The first basic solution can be found using one of the following methods:

1) least cost method .

2) Vogel's Method .

3) Results Approximations Method.

4) Totals Method.

The following is a brief description of the work of each method:

\section{1) A least cost method:}

This method is more efficient, which does not rely on any scientific basis in the selection of basic variables, while this method depends on the selection of the basic variables on the least expensive variable and its allocation and then choose the least expensive variable of the remaining variables and the allocation of it and so repeat the process until The first solution is to obtain $(m+n-1)$ positive values.

2) (Vogel's Method) (Penalty Method):

a. Finding the initial solution to the issue of transport in this way is thus:

b. Calculate the difference between the lowest cost per row and column.

c. Select the largest difference from the step (1) .

d. Select the lowest-cost variable in the row and column corresponding to the selected value in (b) and assign it.

e. Repeat the previous steps until we reach the first solution.

\begin{tabular}{|c|c|}
\hline 5 & 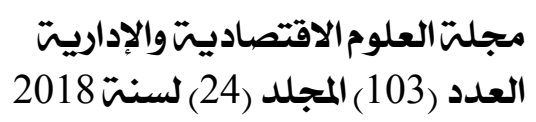 \\
\hline
\end{tabular}




\section{Using modern techniques for determining the location of marketing outlet for product of the state company for vegetables oil}

\section{3) (Results Approximations Method):}

Finding the initial solution to the issue of transport in this way is thus:

a.We choose the highest cost in each row and denote $\left(u_{i}\right)$.

b.We choose the highest cost per column, which is $\left(\mathbf{v}_{\mathbf{j}}\right)$.

c.We apply the following equation $\Delta i j=C_{i j}-U_{i}-V_{j}$

for all values $(\mathbf{i}, \mathbf{j})$.

d.We select the variable with the most negative value in terms of $(\Delta$ ij $)$ and assign it to it.

e.The previous steps are repeated until we reach the initial solution .

4) Total Method:1 -

The work of this method is as follows:

a - Calculates the sum of the cost of the rows.

b - Select the row that represents the lowest total cost.

c - Put each cost of the cost of the grade of less expensive than the cost of the corresponding column. . A row of new costs is made. The highest cost is selected and the allocation is made and the higher cost of the remaining cost is chosen and allocated until the available supply is exhausted and the selection is for positive costs only.

d - The previous steps are repeated until a solution is found which is often the best solution.

e - In the case of two or more rows representing the lowest in terms of the sum of the costs, one of these two grades is chosen.

$f$ - If there is more than one number representing the highest cost in the new cost row, the choice is for the lower cost of the original row costs corresponding to the top in the new cost row.

B - The second stage :

Finding the Optimal Solution:

After reviewing some of the methods used to find the initial solution to the transport issue, there are two methods used to convert the initial solution into an optimal solution:

1 - The Stepping Stone Method.

2 - The Modified Distribution Method.

We will briefly explain the work of method (2) as more efficient than the first method.

Modified Distribution Method:

This method is used to test the optimization of the first solution, which is more efficient than the previous method (the method of winding path), which depends on the formation of closed paths of the non-core variables and then find the non-basic variable, which contributes to reducing the total cost of transport. This method is able to determine the non-fundamental variable, By reducing the total direct transport costs. The steps of this method are summarized as follows: 1 - Find $\left(u_{i}\right)$ values that represent the sources and $\left(v_{i}\right)$ values that represent the sites as: 


\section{Using modern techniques for determining the location of marketing} outlet for product of the state company for vegetables oil

$u_{i}+v_{j}=c_{i j}$. The equation applies to the basic variables (null cells) in the initial solution.

2 - Calculation of the relative cost coefficients of non-core variables Agencies: ( 13)

$$
\left(C_{i j}\right)^{\overrightarrow{ }}=C_{i j}-\left(u_{i}+v_{j}\right) \text {. }
$$

3 - If the relative cost coefficients are positive, this indicates that the initial solution is an optimal solution. If it is negative or contains some negative values, the non-primary variable with the lowest relative cost coefficient (the most negative) is chosen.

4 - Create a closed path of the internal variable chosen in step (3) to determine the number of units that will be allocated to him in the same way as the winding path.

5 - Repeat the previous steps until the best solution is reached.

\section{4 - Practical view:}

In this study, a new market (sales center) is selected for the discharge of the productive flow achieved by the production process and by the proposal of the researcher to increase the profits of these products. The choice of this market will depend on the method of transport after selecting the market which achieves the lowest transfer cost among the proposed and famous markets In the country after knowing that this market can manage this surplus of production, and after consultation with the marketing department in the company, it turns out that the company lacks to open a market in popular neighborhoods where the momentum of a large population was among these markets proposed to open a future market in (Al Sadr City in Baghdad) and through us Of this market in Market No. (17) or a market in ( Al Shiela city in Baghdad ) and we expressed this market market number (18) or a market in the city of (Husseiniya City in Baghdad we expressed this market market no. (19), and these markets can discharge the production surplus realized.

From this point of view, the researcher compared these three markets using the method of transportation to choose the optimal market that achieves the lowest costs to discharge the surplus of the production achieved, thus increasing the profit process successively, depending on the program ( Win QSB ) and expressed by the first section, On the transport schedule which includes the proposed new market and then compare the results of the first and second.

The General Company for Vegetable Oils has 16 markets (sales centers) distributed throughout the country. These markets are supplied from the warehouses of the company's factories (Al-Ameen Factory, Al-Ma'amun Factory, Al-Rasheed Factory). We have expressed these warehouses with (A, B , C) The company's sales to the public and private sectors are another market and are directly processed from these warehouses . (9,12) 


\section{5 - Transportation costs:}

The cost of transporting one kilogram of the product from the warehouse to the direct selling center in Iraqi dinar is as follows :

Note that these transportation costs are taken from the company's transport department, which can be used in transport model

Table (1) Represent Transportation Costs in Iraqi Dinars per kilogram

\begin{tabular}{|c|c|c|c|c|}
\hline No. & Destinations & AL-Ameen & AL- Maamun & AL- Rasheed \\
\hline 1 & Alrasefa & 7 & 6 & 5.5 \\
\hline 2 & Alwklai & 7.5 & 6 & 5 \\
\hline 3 & Alademu & 10 & 9 & 9.5 \\
\hline 4 & Alkademu & 11 & 10 & 10.5 \\
\hline 5 & Alkrada & 10 & 9 & 9.5 \\
\hline 6 & Alkder & 8.5 & 8 & 9 \\
\hline 7 & Albyai & 10 & 11 & 9 \\
\hline 8 & Alsayda & 11 & 11.5 & 10 \\
\hline 9 & Alasheb & 9 & 9.5 & 10 \\
\hline 10 & Almstanse & 8 & 8.5 & 39 \\
\hline 11 & Mosel-right & 40 & 38 & 44 \\
\hline 12 & Mosel-left & 45 & 44 & 32 \\
\hline 13 & Albasra & 32 & 31 & 17 \\
\hline 14 & Babelon & 17 & 18 & 0.75 \\
\hline 15 & Mesan & 27 & 26 & 1 \\
\hline & Company selling & 0.75 & 15 & 8 \\
\hline
\end{tabular}

The total quantity of demands which supply from stat company for vegetables oil to destinations with deferent percents dependently by the information's from marketing department in the company, the follows table represent the percent of each material .

Table (2) represent percents of demands materials

\begin{tabular}{|c|l|c|}
\hline No & \multicolumn{1}{|c|}{ demand of material } & The percent \\
\hline $\mathbf{1}$ & Shampoo & $\mathbf{1 5 \%}$ \\
\hline $\mathbf{2}$ & Alzahe & $\mathbf{1 6 \%}$ \\
\hline $\mathbf{3}$ & Sebon Alsail & $\mathbf{0 8 \%}$ \\
\hline $\mathbf{4}$ & Sebon Alger & $\mathbf{1 0 \%}$ \\
\hline $\mathbf{5}$ & Sebon Altiwlet & $\mathbf{2 0 \%}$ \\
\hline $\mathbf{6}$ & Mesahok Algesel & $\mathbf{1 8 \%}$ \\
\hline 7 & AlKaser & $\mathbf{1 3 \%}$ \\
\hline \multicolumn{2}{|c|}{ Percent total } \\
\hline
\end{tabular}




\section{6 - request quantities of destinations:}

The following request table shows the request made or sold according to the plan for all the markets of the company.

Table (3) Represent Request verified ( k. g )

\begin{tabular}{|c|c|c|}
\hline N & Destinations & Request verified \\
\hline 1 & Alrasefa & 622100 \\
\hline 2 & Alwkla & 243201 \\
\hline 3 & Alademu & 87035 \\
\hline 4 & Alkadem & 106183 \\
\hline 5 & Alkrada & 94931 \\
\hline 6 & Alkder & 36747 \\
\hline 7 & Albya & 24008 \\
\hline 8 & Alsayda & 97164 \\
\hline 9 & Alasheb & 87927 \\
\hline 10 & Almstanse & 95284 \\
\hline 11 & Mosel-left & 86434 \\
\hline 12 & Mosel-right & 55181 \\
\hline 13 & Albasra & 97320 \\
\hline 14 & Babelon & 50037 \\
\hline 15 & Mesan & 30526 \\
\hline 16 & Company selling & 929922 \\
\hline \multicolumn{2}{|r|}{ total } & 2744000 \\
\hline
\end{tabular}

\section{7 - Quantities of supply from sources:}

The following table shows the quantities produced from each factory of the production factories, which represent the sources in the transportation model (sources), in which a statement of the surplus quantity produced by the factories as follows: 


\section{Using modern techniques for determining the location of marketing outlet for product of the state company for vegetables oil}

Table (4) Represent Supply of products from each factory ( k.g)

\begin{tabular}{|c|c|c|c|c|c|c|c|c|c|}
\hline \multirow{2}{*}{ No. } & factory & \multicolumn{2}{|c|}{ AL- Amine } & \multicolumn{2}{|c|}{ AL-Mamoon } & \multicolumn{2}{|c|}{ AL-Rashed } & \multicolumn{2}{|c|}{ total } \\
\hline & production & Request & surplus & Request & surplus & $\begin{array}{c}\text { Reques } \\
\mathbf{t}\end{array}$ & surplus & Request & surplus \\
\hline 1 & Shambo & & & 218000 & 7000 & & & 218000 & 7000 \\
\hline 2 & Alzahe & 100000 & 2000 & 525000 & 13000 & 125000 & 3000 & 750000 & 18000 \\
\hline 3 & Alsebon sael & 211000 & 8000 & & & & & 211000 & 8000 \\
\hline 4 & Sebon Alger & 475000 & 30000 & & & & & 475000 & 30000 \\
\hline 5 & Sebon Altwlet & 130000 & 11000 & 225000 & 19000 & 35000 & 3000 & 390000 & 33000 \\
\hline 6 & $\begin{array}{l}\text { Meshok } \\
\text { Algesel }\end{array}$ & & & 183000 & 49000 & 262000 & 71000 & 445000 & 120000 \\
\hline 7 & Algaser & 80000 & 13000 & 175000 & 29000 & & & 255000 & 42000 \\
\hline & total & 996000 & 64000 & 1326000 & 117000 & 422000 & 77000 & 2744000 & 258000 \\
\hline & total all & \multicolumn{2}{|c|}{1060000} & \multicolumn{2}{|c|}{1443000} & \multicolumn{2}{|c|}{499000} & \multicolumn{2}{|c|}{3002000} \\
\hline
\end{tabular}

\section{8 - Creating of transport model:}

The transport model for this problem contains three sources, namely the three factories' warehouses (AL- Amien , Al-Ma'amoon, Al-Rasheed ). These sources are referred to in this model as( $\mathrm{A}, \mathrm{B}$ and $\mathrm{C})$. The quantities of supply for these sources are shown In the table (4), which is (the factory the AL-Amien of the $A=1060000)$, (Al-Ma'amoun factory $B=1443000)$, (Al-Rasheed factory $\mathrm{C}=499000$ ), totaling $3002000 \mathrm{~kg}$, this model contain (16) of destinations Demand, represented by markets or sales centers of the company were referred to these sites numbers from (1) to (16) as shown in Table (3), but the quantities of demand for these sites (2744000). In this case, we will have an unbalanced transport model due to the difference between the quantity of supply which is more than the quantity of demand, As we knew in transport cases in such a case. During the addition of a market Dummy and the cost of zeros and placed against this market the excess quantity, but the researcher replaced the dummy market with a new market and real cost to manage the current production flow to choose a new market of the three markets suggested to be three tables the number of markets suggested and then choose the market Which achieves the lowest costs, was a Consultation on this subject with the Department of Marketing to select these locations, which is the location No. (17) in Sadr City and the cost $(10,11,11)$ and the location number $(18)$ in shiala city of the torch and the cost $(11,11,12)$ and location (19) in the Husseiniya city and the cost $(12,12,13)$ The following table shows the transport model of the problem as follows: 


\section{Using modern techniques for determining the location of marketing}

outlet for product of the state company for vegetables oil

\section{Table (5) Represent Transportation problem}

\begin{tabular}{|c|c|c|c|c|c|c|c|c|c|c|c|c|c|c|c|c|c|}
\hline & 1 & 2 & 3 & 4 & 5 & 6 & 7 & 8 & 9 & 10 & 11 & 12 & 13 & 14 & 15 & 16 & Supply \\
\hline $\mathbf{A}$ & 7 & 7.5 & 10 & 11 & 10 & 8,5 & 10 & 11 & 9 & 8 & 40 & 45 & 32 & 17 & 27 & 0.75 & 1060000 \\
\hline B & 6 & 6 & 9 & 10 & 9 & 8 & 11 & 11.5 & 9.5 & 8.5 & 38 & 44 & 31 & 18 & 26 & 1 & 1443000 \\
\hline C & 5.5 & 5 & 9.5 & 10.5 & 9.5 & 9 & 9 & 10 & 10 & 8 & 39 & 44 & 32 & 17 & 25 & 0.75 & 499000 \\
\hline & 622100 & 243201 & 87035 & 106183 & 94931 & 36747 & 24008 & 97164 & 87927 & 95284 & 86434 & 55181 & 97320 & 50037 & 30526 & 929922 & $\begin{array}{l}3002000 \\
2744000\end{array}$ \\
\hline
\end{tabular}

From the above table we find that it is unbalanced due to the production gap and the difference of $\mathbf{2 5 8 0 0 0}$ productive units. Instead of balancing the table with a dummy market with zeros cost, we will put a real market and the cost is known, as will be seen in the first section.

\section{The first section:}

The balance of the table (5) with a new market proposed for the disposal of the productive flow, which is Market No. 17, Market No. 18 and Market No. 19, and with the known costs which we have indicated in advance and on this basis we have three tables for three suggested markets and choose ones of markets throw optimal solution table by using (Win QSB) program which achieves the lowest costs as shown in the following solution tables:

Table (6) Represent Solving the transport model by adding market number (17)

\begin{tabular}{|c|c|c|c|c|c|c|}
\hline $04-20-2013$ & From & To & Shipment & Unit Cost & Total Cost & Reduced Cost \\
\hline 1 & A & $\mathbf{9}$ & 87927 & $\mathbf{9}$ & 791343 & $\mathbf{0}$ \\
\hline 2 & A & 10 & 95284 & $\mathbf{8}$ & 762272 & $\mathbf{0}$ \\
\hline 3 & A & 14 & 50037 & 17 & 850629 & $\mathbf{0}$ \\
\hline 4 & A & 16 & 826752 & 0.75 & 620064 & $\mathbf{0}$ \\
\hline 5 & $\mathbf{B}$ & 1 & 622100 & 6 & 3732600 & $\mathbf{0}$ \\
\hline 6 & $\mathbf{B}$ & 2 & 153899 & $\mathbf{6}$ & 923394 & $\mathbf{0}$ \\
\hline 7 & B & 3 & 87035 & $\mathbf{9}$ & 783315 & $\mathbf{0}$ \\
\hline 8 & B & 4 & 106183 & 10 & 1061830 & $\mathbf{0}$ \\
\hline 9 & B & 5 & 94931 & $\mathbf{9}$ & 854379 & $\mathbf{0}$ \\
\hline 10 & B & 6 & 36747 & $\mathbf{8}$ & 293976 & $\mathbf{0}$ \\
\hline 11 & B & 11 & 86434 & 38 & 3284492 & $\mathbf{0}$ \\
\hline 12 & B & 12 & 55181 & 44 & 2427964 & $\mathbf{0}$ \\
\hline 13 & B & 13 & 97320 & 31 & 3016920 & $\mathbf{0}$ \\
\hline 14 & B & 16 & 103170 & 1 & 103170 & $\mathbf{0}$ \\
\hline 15 & $\mathbf{C}$ & 2 & 89302 & 5 & 446510 & $\mathbf{0}$ \\
\hline 16 & $\mathbf{C}$ & 7 & 24008 & 9 & 216072 & $\mathbf{0}$ \\
\hline 17 & $\mathbf{C}$ & $\mathbf{8}$ & 97164 & 10 & 971640 & $\mathbf{0}$ \\
\hline 18 & $\mathbf{C}$ & 15 & 30526 & 25 & 763150 & $\mathbf{0}$ \\
\hline \multirow[t]{2}{*}{19} & $\mathbf{C}$ & 17 & 258000 & 10 & 2580000 & $\mathbf{0}$ \\
\hline & Total & Objective & Function & Value $=$ & $2.448372 E+07$ & \\
\hline
\end{tabular}


Using modern techniques for determining the location of marketing outlet for product of the state company for vegetables oil

Table (7) Represent Solving the transport model by adding market number (18)

\begin{tabular}{|c|c|c|c|c|c|c|}
\hline 04-20-2013 & From & To & Shipment & Unit Cost & Total Cost & Reduced Cost \\
\hline 1 & A & $\mathbf{9}$ & 87927 & $\mathbf{9}$ & 791343 & $\mathbf{0}$ \\
\hline 2 & A & 10 & 95284 & $\mathbf{8}$ & 762272 & $\mathbf{0}$ \\
\hline 3 & A & 14 & 50037 & 17 & 850629 & $\mathbf{0}$ \\
\hline 4 & A & 16 & 826752 & 0.75 & 620064 & $\mathbf{0}$ \\
\hline 5 & $\mathbf{B}$ & 1 & 517999 & $\mathbf{6}$ & 3107994 & $\mathbf{0}$ \\
\hline 6 & $\mathbf{B}$ & 3 & 87035 & $\mathbf{9}$ & 783315 & $\mathbf{0}$ \\
\hline 7 & B & 4 & 106183 & 10 & 1061830 & $\mathbf{0}$ \\
\hline $\mathbf{8}$ & $\mathbf{B}$ & 5 & 94931 & $\mathbf{9}$ & 854379 & $\mathbf{0}$ \\
\hline 9 & B & 6 & 36747 & $\mathbf{8}$ & 293976 & $\mathbf{0}$ \\
\hline 10 & $\mathbf{B}$ & 11 & 86434 & 38 & 3284492 & $\mathbf{0}$ \\
\hline 11 & $\mathbf{B}$ & 12 & 55181 & 44 & 2427964 & $\mathbf{0}$ \\
\hline 12 & $\mathbf{B}$ & 13 & 97320 & 31 & 3016920 & $\mathbf{0}$ \\
\hline 13 & $\mathbf{B}$ & 16 & 103170 & 1 & 103170 & $\mathbf{0}$ \\
\hline 14 & $\mathbf{B}$ & 18 & 258000 & 11 & 2838000 & $\mathbf{0}$ \\
\hline 15 & $\mathbf{C}$ & 1 & 104101 & 5.50 & $572,555.50$ & $\mathbf{0}$ \\
\hline 16 & $\mathbf{C}$ & 2 & 243201 & 5 & 1216005 & $\mathbf{0}$ \\
\hline 17 & $\mathbf{C}$ & 7 & 24008 & 9 & 216072 & $\mathbf{0}$ \\
\hline 18 & $\mathbf{C}$ & $\mathbf{8}$ & 97164 & 10 & 971640 & $\mathbf{0}$ \\
\hline \multirow[t]{2}{*}{19} & $\mathbf{C}$ & 15 & 30526 & 25 & 763150 & $\mathbf{0}$ \\
\hline & Total & Objective & Function & Value $=$ & $2.453577 E+07$ & \\
\hline
\end{tabular}

Table (8) Represent Solving the transport model by adding market number (19)

\begin{tabular}{|c|c|c|c|c|c|c|}
\hline $04-20-2013$ & From & To & Shipment & Unit Cost & Total Cost & Reduced Cost \\
\hline 1 & A & 9 & 87927 & 9 & 791343 & 0 \\
\hline 2 & A & 10 & 95284 & 8 & 762272 & 0 \\
\hline 3 & A & 14 & 50037 & 17 & 850629 & 0 \\
\hline 4 & A & 16 & 826752 & 0.75 & 620064 & 0 \\
\hline 5 & B & 1 & 517999 & 6 & 3107994 & 0 \\
\hline 6 & B & 3 & 87035 & 9 & 783315 & 0 \\
\hline 7 & B & 4 & 106183 & 10 & 1061830 & 0 \\
\hline 8 & B & 5 & 94931 & 9 & 854379 & 0 \\
\hline 9 & B & 6 & 36747 & 8 & 293976 & 0 \\
\hline 10 & B & 11 & 86434 & 38 & 3284492 & 0 \\
\hline 11 & B & 12 & 55181 & 44 & 2427964 & 0 \\
\hline 12 & B & 13 & 97320 & 31 & 3016920 & 0 \\
\hline 13 & B & 16 & 103170 & 1 & 103170 & 0 \\
\hline 14 & B & 17 & 258000 & 12 & 3096000 & 0 \\
\hline 15 & C & 1 & 104101 & 5.50 & $572,555.50$ & 0 \\
\hline 16 & C & 2 & 243201 & 5 & 1216005 & 0 \\
\hline 17 & C & 7 & 24008 & 9 & 216072 & 0 \\
\hline 18 & C & 8 & 97164 & 10 & 971640 & 0 \\
\hline 19 & C & 15 & 30526 & 25 & 763150 & 0 \\
\hline \hline & Total & $0 b j e c t i v e$ & Function & Value & 2.479377 E+07 & \\
\hline
\end{tabular}




\section{Using modern techniques for determining the location of marketing}

outlet for product of the state company for vegetables oil

After comparing the three markets $(17,18,19)$, market 17 was found to be the best among these markets, as shown in the tables of solution (6), (7), (8,and the transportation cost equal (24483720) dinars, when adding suggest market No. (17), while the cost of transportation by adding the suggest market No. (18) cost equal (24535770) dinars, and the cost of transport by adding market suggest No. (19) (24793770) dinars.

The second section :

To solving the transportation model of adding market number 17 to all models of transport that achieve the first solution (Rossell method, total method, Vogel method, Northwest corner method, less cost method) In the solution and then compare the result of the first section to know the best solutions in such subjects exposed to the production and marketing facilities and the following tables show the solution of the transport model by using all methods of solution.

Table (9) Represent Solution by using least cost method

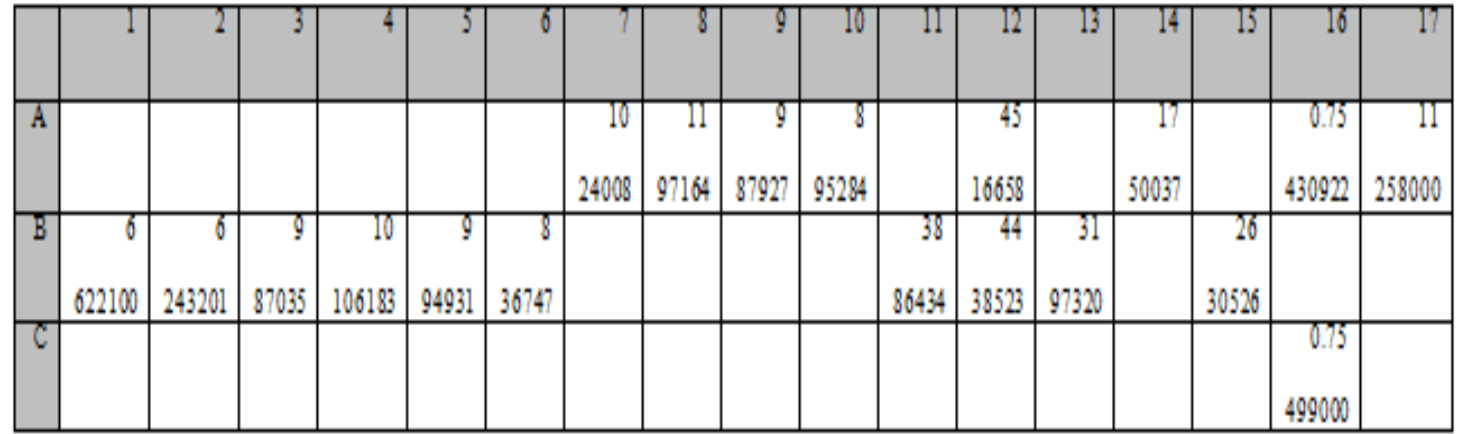

Result of the table solution $=\mathbf{2 4 9 7 3 5 8 5 . 5}$ dinars

Table (10) Represent Solution by using the approximate Vogel method

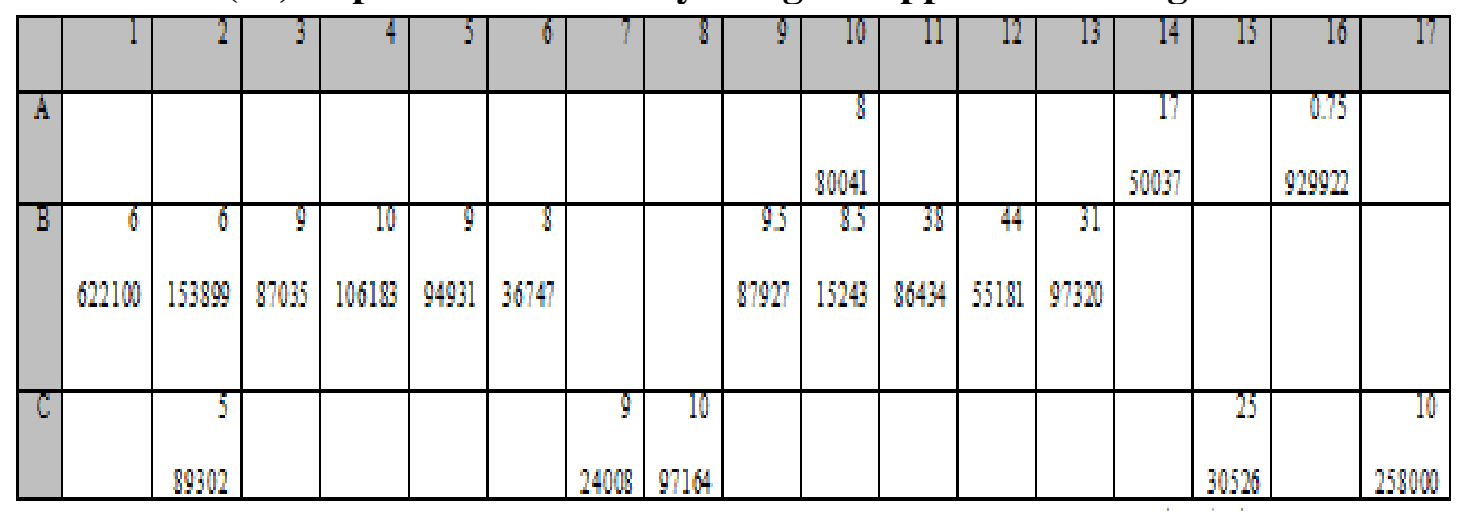

Result of the table solution $=\mathbf{2 4 5 0 9 5 1 2 . 5}$ dinars 
Using modern techniques for determining the location of marketing outlet for product of the state company for vegetables oil

Table (11) Represent Solution by total method

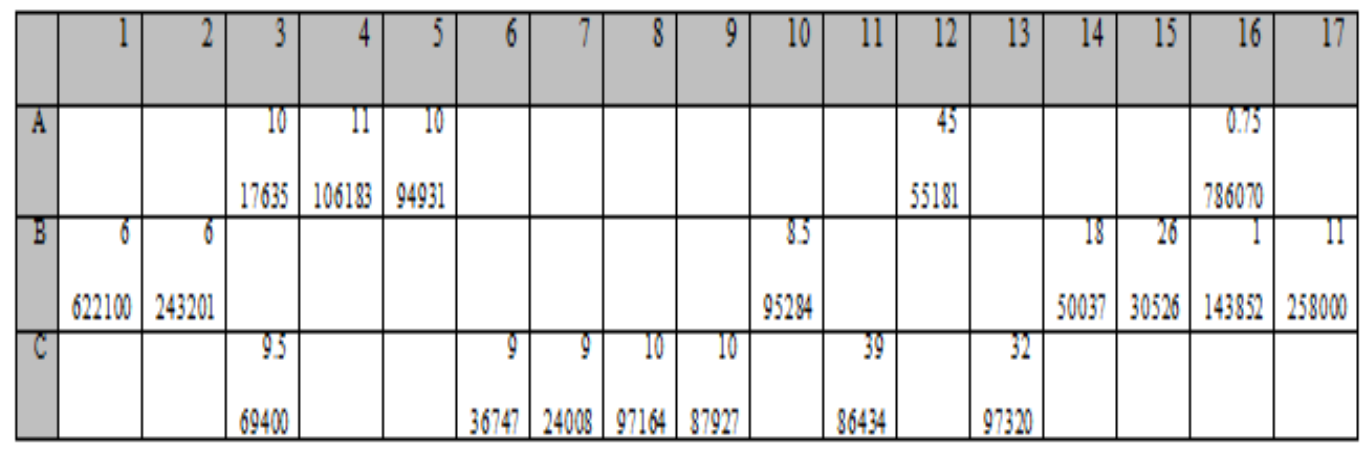

The result of the solution table $=\mathbf{2 4 6 7 9 4 5 3 . 5}$ dinars

Table (12) Represent Solution by using Roussel approximate method

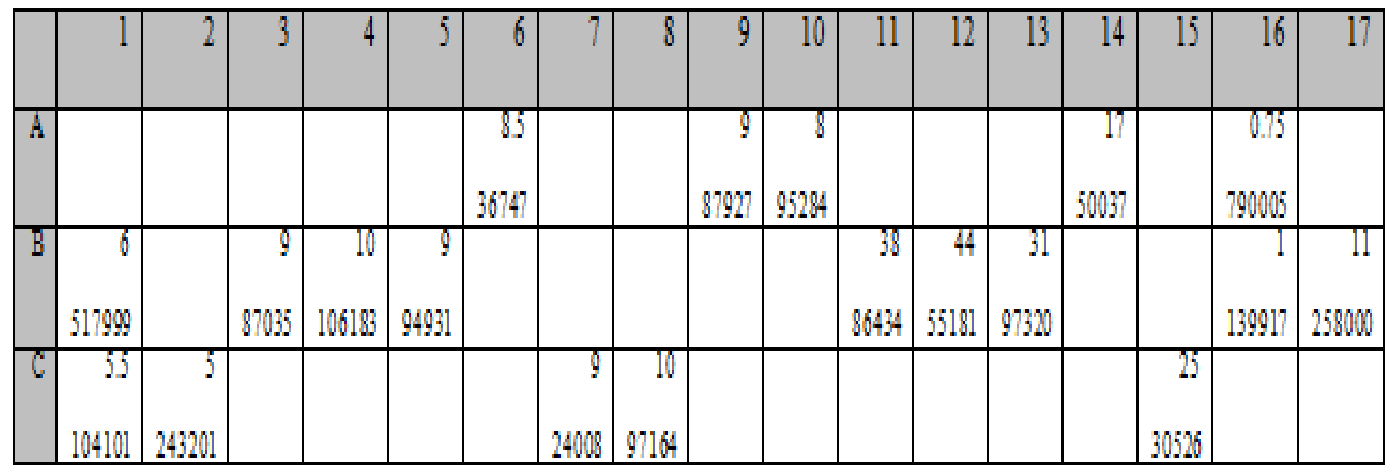

Result of the table solution $=\mathbf{2 4 5 6 3 3 3 0 . 7 5}$ dinars

\section{A results:}

In the previous tables, it is clear that the table of the first solution that achieves the lowest costs is Table (11) in the approximate Vogel method, which shows that the solution in this way is better than the rest of the methods mentioned. This first solution was tested in the modified distribution method. $\left.(\mathrm{Cij}) \overrightarrow{ }{ }^{\overrightarrow{ }}=\mathbf{7 4 1 . 7}\right)$ , but the total real variables $(\mathrm{Cij}=\mathbf{7 7 6})$

By using the following formula, it is clear that this solution is optimal ( - $\mathrm{Cij} \leq 0$ $\overrightarrow{\mathrm{Cl}}$ )

In conclusion, the comparison between the result of Table (11) in the approximate Vogel method resulting in (24509512.5) dinars and the result of Table (6) in the first section, which result (24483720), it is found that the solution through the program ( Win QSB ) achieves the best solutions.

\section{9 - Conclusions}




\section{Using modern techniques for determining the location of marketing outlet for product of the state company for vegetables oil}

1 - The company suffers from weakness in the preparation of plans for production, where it emerged that there is a significant discrepancy between the annual plan and the quantities of production achieved, indicating that the company does not rely on scientific methods in the development of production schemes, but be relying on traditional methods rely on the basis of experience and data Historical production.

2 - There is no coordination and harmony between the sections of the company in accordance with the productive interest and the development of annual production plans accurately, we find that the Planning Department sets annual plans without knowing what can be provided from the raw materials from the control of the treasury and without knowledge of the costs of production, The marketing department gives expectations for demand based on guessing and product marketing is random and without prior study. Using the transport model for the purpose of distributing the products to the sales centers in an optimal manner as well as comparison through this model between three suggested markets and choosing the model that achieves the lowest costs and through which the choice is made on the market (17) and (18) and (19). The choice of market (17) in transport table (6), which achieves least costs.

\section{0 - Recommendations:}

1 - The need to provide a common database for all the company's products by the planning department, the marketing department, the control department, the cost accounting department, and the continuous coordination between the company departments to develop the appropriate production and marketing plans for the company's products.

2 - The necessity of involving the staff in the Planning and Production Department with developmental and rehabilitation courses, especially the importance of modern production systems and how to benefit from them in the field of preparing production plans and monitoring the storage and production processes through training on the applications of these systems in coordination with universities and scientific centers for the establishment of these courses.

3 - The emergence of the need to import new machines, especially the canning machines because most of the machines old and produce undesirable forms, it is necessary to use modern designs in the appearance of the external appearance of the product, especially after the qualitative boom reached by the field of packaging in the world.

4 - The company should pay attention to the policy of publicity and advertising, that is to develop a modern marketing policy for the products of the company and through the opening of training courses for employees in order to raise production efficiency and development. 


\section{The References:}

1-Al Janabi, d. Hussein Mahmoud, "The Latest in Operations Research", Dar Al-Hamed Publishing and Distribution, Amman-Jordan, 2010.

2- Al-Shamarti, Prof. Hamid Saad Nour, "Operations Research Concept and Application", Memory Library, Baghdad, Iraq, First Edition, 2010.

3- Al-Shamarti, Hamed Saad Nour and Zubaidi Ali Khalil, "Introduction to Operations Research", Dar Majdalawi Publishing and Distribution, AmmanJordan, First Edition, 2007.

4 - Amiri, d. Saleh Mahdi and Awatif Ibrahim Al-Haddad, "Applications of Operations Research in Management", Thira Publishing and Distribution, Amman-Jordan, First Edition, 2009.

5-Bashaiwa, d. Hassan Abdalla, "Operations Research", Dar Al-Yazoury Operation for Publishing and Distribution, Amman-Jordan, Arabic Edition, 2011. 6-Gass, Saul I. "Linear Programming Methods and Applications", McGrawHill Books company, New York, USA, $5^{\text {th }}$ edition, 1985.

7- Gupta, Permkumer\& Dr. Hira, "Operation Research", S. Chand \& company LTD, New Delhi- India, 2011.

8- Hamdan, Fathi Khalil, Petra University, "Operations Research with Computer Applications", Dar Wael Publishing and Distribution, AmmanJordan, First Edition, 2010.

9- Heller, F. S. And J. T. , " Lieberman, Introduction to Operations Research ", Farouk Ressam et al., Military Technical College - Baghdad, First Edition, 1987 . 10- Hitchcock "Operation Research Models and Methods" 1941.

11- Jensen, Paul A. \& Jonathan F. Bard, "Operation Research Models and Methods", ,2003.

12- Koopmans, Cooper and Charnes "Operation Research Models and Methods"1953 .

13-Taha, H. A. ,"Operation Research An introduction", pearsonprentice Hall, New Jersey, $9^{\text {th }}$ edition, 2011. 


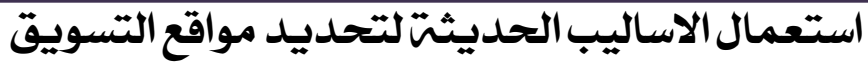

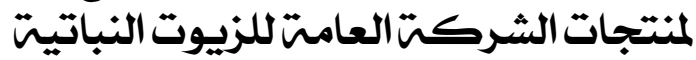

$$
\begin{aligned}
& \text { أ. م. د.عبد المنعم كاظم الشكري/ كليت الادارة والاقتصاد/ جامعت بغداد }
\end{aligned}
$$

اعدت هذه الدراسة على مبحثين، حيث تضمن المبحث الاول المقارنة بين الاسواق المقترحة من خلال

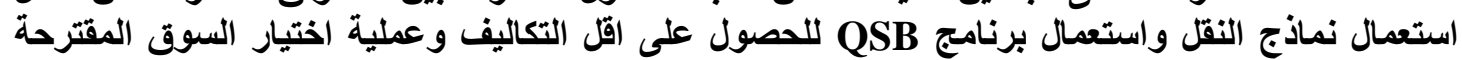

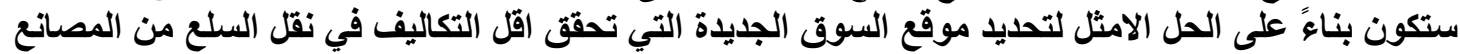

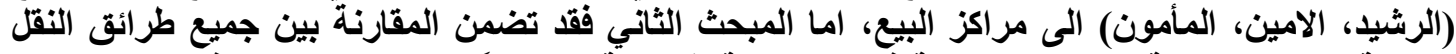

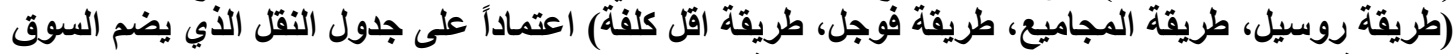

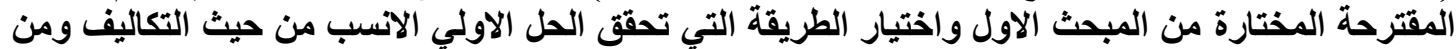

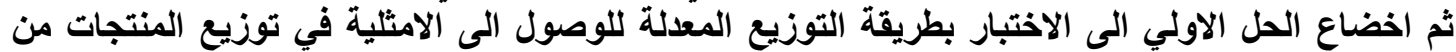

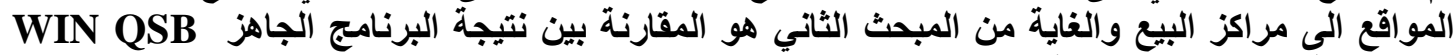

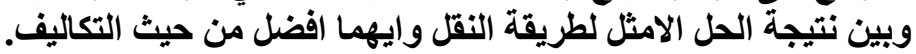

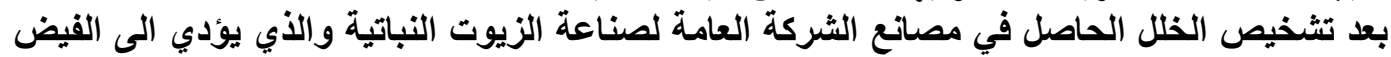

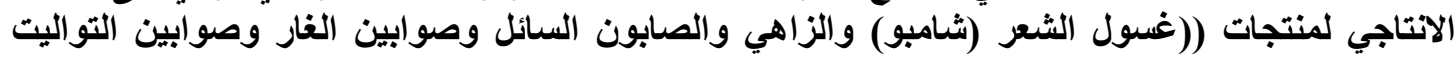

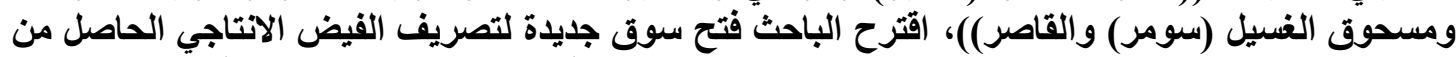

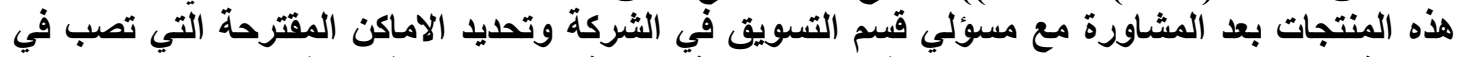

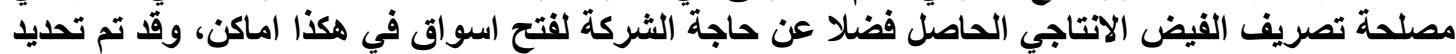

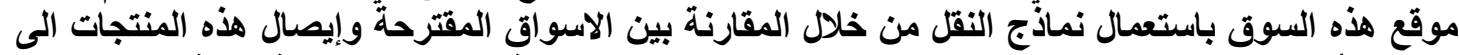

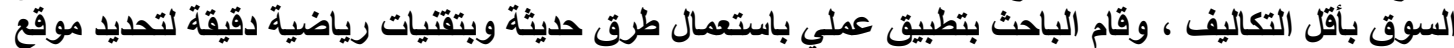

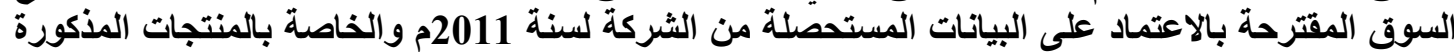

الصطاحات الرئيسة للبحث / أنموذج النقل، البرمجة الخطية، المصادر، مركز الطلب، موقع،

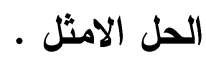

